\section{Short-term immunotoxic effects of an anti-cancer drug (Etoposide) on the freshwater pondsnail Lymnaea stagnalis}

\author{
P. Boisseaux, ${ }^{1}$ M. Gust, ${ }^{1}$ S. Betoulle, ${ }^{2}$ \\ J. Garric ${ }^{1}$ \\ 'Laboratory of Ecotoxicology, IRSTEA \\ Lyon-Villeurbanne, Villeurbanne; \\ 2Université de Reims Champagne- \\ Ardenne, UMR-I 02 SEBIO Stress envi- \\ ronnementaux et Biosurveillance des \\ milieux aquatiques, Reims, France
}

\section{Introduction}

A growing body of evidences indicates the rise in pharmaceutical contamination of aquatic ecosystems. ${ }^{1-3}$ Anti-cancer drugs (AKs) are very special because they may avoid some toxicological studies, clinical trials or environmental toxicity assessments imposed for other pharmaceuticals (EMEA, FDA) ${ }^{4-6}$ In parallel, these drugs require high dosage. It generates high amounts of biologically active molecules into hospital effluents and by extension into surface waters. Both parent-compounds and metabolites are being encountered at high concentrations (ng/L to $\mu \mathrm{g} / \mathrm{L}){ }^{7,8}$ The original molecules may be generated from the fraction non-metabolized by humans ( $\cong 0.40$ for etoposide). ${ }^{8}$ Eventually, it may be the result of accidental spillages or lack of environmental good practices.

Among AKs, Etoposide is widely used in chemotherapy (total amount consumed in France in 2004 was $332.84 \mathrm{~kg}$ ). ${ }^{7}$ It is prescribed worldwide against lung, testicles and blood cells (lymphoma) cancers in humans. ${ }^{9,10}$ This plant-derived alkaloid is an anti-neoplasmic, cytotoxic molecule reported to cause single DNA breaks with topoisomerase II inhibiting effects. It has been detected at concentrations up to $5 \mu \mathrm{g} / \mathrm{L}$ in cancer-specialized hospital effluents. ${ }^{8}$

The pond snail Lymnaea stagnalis inhabits lentic freshwater systems and is ecologically relevant in Holarctic regions of the planet (i.e. northern hemisphere). This gastropod is currently recommended by OECD for full-lifecycle toxicity testing. ${ }^{11}$ Hemocytes are the circulating immunocompetent cells of Lymnaea stagnalis' open immune system. Their lymphatic concentration is directly linked to the immune capacity.

Immune response substantially depends on phagocytosis. Immunosuppressive effects can increase its vulnerability to multiple biological stressors (such as pathogen invasions) and impair its population. ${ }^{12}$ We aimed at assessing the acute effects of Etoposide on $L$. stagnalis' immune parameters, both at environmentally realistic concentrations and at therapeutic-like concentrations. ${ }^{10}$

\section{Materials and Methods}

\section{Experimental conditions \\ and \\ chemical exposure}

Calibrated laboratory-reared adult pondsnails $(30 \pm 1 \mathrm{~mm}$ shell-length) were acclimated during $24 \mathrm{~h}$ in $500 \mathrm{~mL}$ beakers filled with clean groundwater. Six replicates of 2 snails (12 snails) were exposed to each condition: one control condition corresponding to clean groundwater, one control supplemented with vehicle solvent $(0.1 \%$ DMSO used for all the tested concentrations) and four Etoposide concentrations (1, 10, 100 and $1000 \mu \mathrm{g} / \mathrm{L}$ ) [Sigma-Aldrich, CAS: 334 19-42-0]. Water was renewed daily under each exposure condition. The lowest concentrations were chosen according to the environmentally-realistic concentrations in hospital effluents $(5 \mu \mathrm{g} / \mathrm{L}){ }^{8}{ }^{8}$ The highest therapeutic-like concentrations were chosen according to cytotoxic effects observed in human plasma concentrations at 0.7-2 $\mu \mathrm{g} / \mathrm{mL}^{10}{ }^{10}$ Exposure temperature was set at $20^{\circ} \mathrm{C}$, constantly recorded and a neon lightning (1000 lux) allowed a photoperiod of $16 \mathrm{~h} / 8$ h (light/dark). Organisms were fed ad libitum with ground TetraPhyll ${ }^{\circledR}(30 \mathrm{mg} / \mathrm{snail})$. During the test, mortality and water parameters (dissolved oxygen, ammoniac, $\mathrm{pH}$, conductivity) were daily measured. The exposure lasted for three days (72 h).

\section{Hemolymph collection}

\section{and flow cytometry analysis}

Hemolymph samples were collected with a micropipette by gently tickling the snail foot sole. Hemocyte density and viability were immediately measured. Acquisitions were performed on a Guava easyCyte TM 6-HT multicolor flow cytometer (Merck Millipore) using the GuavaSoft 2.7 software. The ViaCount module was used for cell density and viability determination, whereas the Incyte module was used for the phagocytosis assessment. Total hemocyte density (THD) and viability were measured using Viacount reagent. Briefly, hemolymph was diluted (1:4) with the reagent into 96-well plates (Costar ${ }^{\circledR}$, sterile, U-bottom, non-treated, polystyrene) and incubated 10 min (in the dark and under slow agitation). In total, 1000 events per sample were acquired. Regarding the phagocytosis, $200 \mu \mathrm{L}$ of hemolymph collected from each individual were disposed onto a 96-well plate (Greiner ${ }^{\circledR}$ bio one, for cell cultures, sterile, F-bottom, polystyrene). An excess amount of $7.5 \times 10^{5}$
Correspondence: Paul Boisseaux, Laboratory of Ecotoxicology, IRSTEA Lyon-Villeurbanne, 5 rue de la Doua, 69626 Villeurbanne, France.

E-mail: paul.boisseaux@irstea.fr

Key words: etoposide, immunotoxicity, acute exposure, pond snail.

Conference presentation: ECOBIM meeting, 2014 May, Brest, France.

Acknowledgements: the region Rhône-Alpes grants a PhD fellowship to Paul Boisseaux. This study was supported by the French IMOPHAK project (Impacts moléculaires, cellulaires et physiologiques de pharmaceutiques anti-cancéreux sur un organisme d'eau douce)

This work is licensed under a Creative Commons Attribution NonCommercial 3.0 License (CC BYNC 3.0).

(C) Copyright P. Boisseaux et al., 2014

Licensee PAGEPress, Italy

Journal of Xenobiotics 2014; 4:4894

doi:10.4081/xeno.2014.4894

latex microbeads (polyscience YG $2.0 \mu$ m latex microsphere) were gently mixed with each sample. Plates were incubated for $24 \mathrm{~h}$ in the dark under gentle agitation. The supernatant was removed and cells were fixed (PBS containing $0.5 \%$ of formaldehyde $(\mathrm{v} / \mathrm{v})$ and $0.2 \%$ $(\mathrm{w} / \mathrm{v})$ of sodium azide). 20,000 events/sample were acquired and read in the YELLOW photomultiplicator $(583 / 26 \mathrm{~nm})$. Calculations were performed as follows: active hemocytes were the proportion of cells that engulfed at least one microbead, whereas the mean number of microbeads per active hemocytes reflects the activity of phagocytosis.

\section{Statistical analysis}

Statistical analyses were performed by running a Kruskal-Wallis Test followed by repeated pairwise Wilcoxon post hoc tests when necessary to compare exposed groups with the control group. The result was considered statistically significant when $\mathrm{P}<0.05 \quad\left({ }^{* *} \mathrm{P}<0.001\right.$ while $\left.{ }^{*} \mathrm{P}<0.05\right)$. Beforehand, the Shapiro test for normality distribution and Bartlett test for homogeneity of variances were run for each group. All statistical analysis were realized with the open source R software. ${ }^{13}$

\section{Results and Discussion}

At therapeutic concentrations (100-1000 $\mu \mathrm{g} / \mathrm{L})$, a sharp drop of total hemocyte density (THD) was observed (Figure 1A). It is consistent with previous studies reporting cytotoxic effects on human blood cells at such concen- 
trations. ${ }^{14}$ At the environmentally relevant concentrations a significant increase in hemocyte density was observed compared to controls (Figure 1A). Similar results have already been observed in $L$. stagnalis at environmentally realistic concentrations of several xenobiotics. ${ }^{15-17}$ Hemocytes viability significantly decreased with increasing drug concentration (Figure 1B). No significant effects were measured on phagocytosis activity. The proportion of active hemocytes is similar under all exposure conditions (approximately 20\%, Figure 1C). Phagocytosis activity was around a mean of 2.9 microbeads per hemocyte in all treatments (Figure 1D).

\section{Conclusions}

Our study highlights the immune disruptive effects of etoposide on the pond snail $L$. stagnalis. At realistic concentrations found in effluents of oncology-specialized hospitals, it exerts immunomodulation effects, whereas at therapeutic-like concentrations the effects become immunosuppressive (cytotoxicity). In addition to this reduced number of hemocytes, a high cellular mortality rate was observed (up to $40 \%)$. However, it seems that phagocytosis carried out by the remaining viable cells was unaffected. It indicates that etoposide is rather cytotoxic than blocks phagocytosis pathways. This experimentation constitutes a first acute
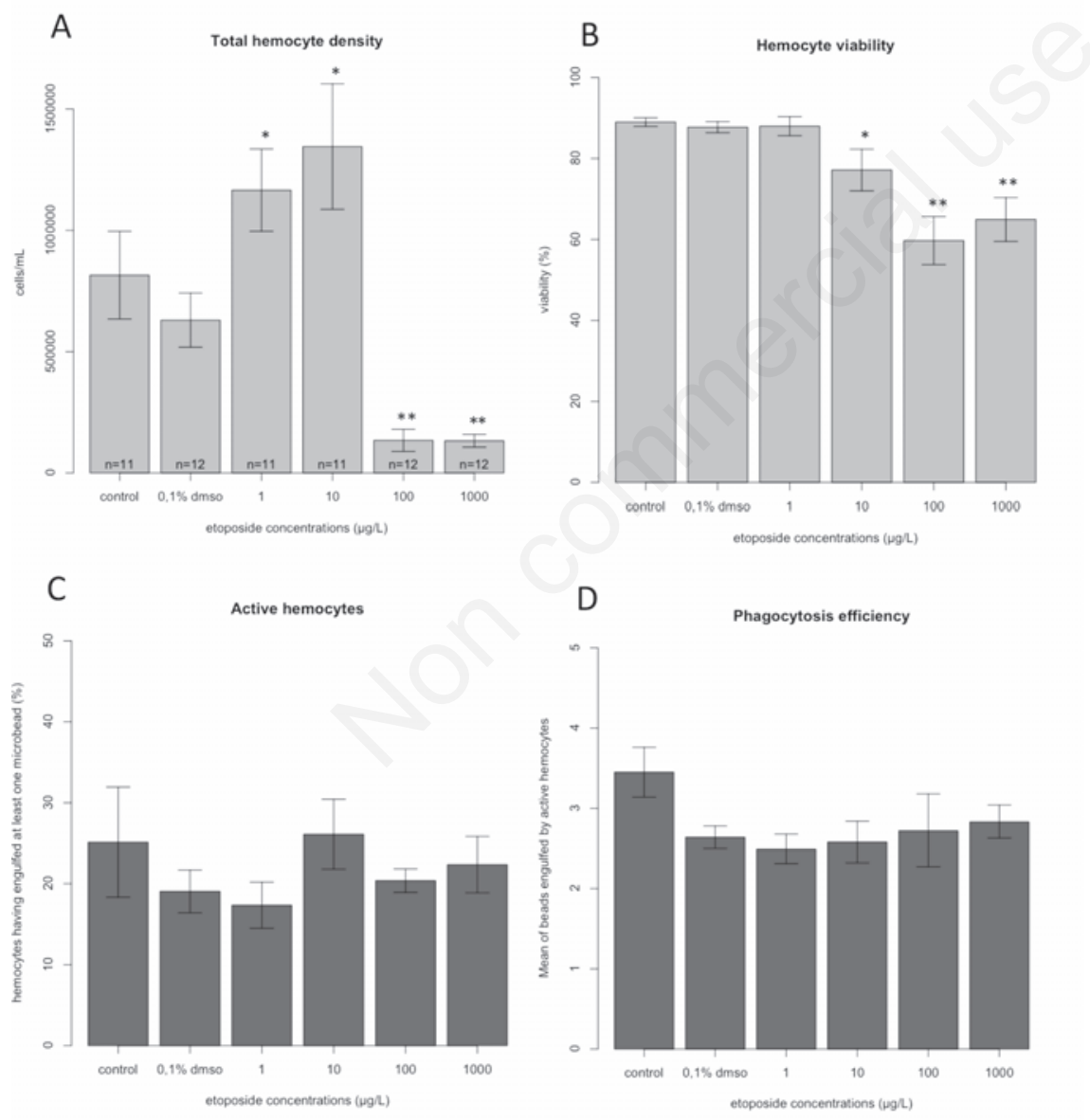

Figure 1. Effects of etoposide on immunocompetence of $L$. stagnalis. Snails were exposed to increasing concentrations of etoposide $(1-1000 \mu \mathrm{g} / \mathrm{L})$ for $72 \mathrm{~h}$ in glass beaker replicates with daily renewals. Afterwards, the hemolymph was collected individually and analyzed for determination of hemocyte concentrations (A), hemocytes viability (B), active phagocytes $(\mathrm{C})$ and efficiency of phagocytosis $(\mathrm{D})$. The barplots and error bars represent the mean and standard error of the mean (SEM) of respective replicates per conditions. The number of snails per condition is indicated at the bottom of the barplots (A); differences correspond to snails that died during the experiment.

approach and further studies are required to clarify: i) the underlying mechanism of actions that lead to the observed increase in hemocytes density at low concentrations; ii) the effects of a chronic exposure; and iii) the further consequences on physiological functions such as growth and reproduction.

\section{References}

1. Kummerer K. The presence of pharmaceuticals in the environment due to human use-present knowledge and future challenges. J Environ Manage 2009;90:235466.

2. Christensen FM. Pharmaceuticals in the environment - a human risk? Regul Toxicol Pharmacol 1998;28:212-21.

3. Matozzo V. Effects of pharmaceuticals on immune parameters of aquatic invertebrates. ISJ 2014 [In press].

4. Dagher R, Johnson J, Williams G, Keegan P, Pazdur R. Accelerated approval of oncology products: a decade of experience. $\mathrm{J}$ Natl Cancer Inst 2004;96:1500-9.

5. Hartmann M, Mayer-Nicolai C, Pfaff 0. Approval probabilities and regulatory review patterns for anticancer drugs in the European Union. Crit Rev Oncol Hematol 2013;87:112-21.

6. Apolone G, Joppi R, Bertele V, Garattini S. Ten years of marketing approvals of anticancer drugs in Europe: regulatory policy and guidance documents need to find a balance between different pressures. Br J Cancer 2005;93:504-9.

7. Besse JP, Latour JF, Garric J. Anticancer drugs in surface waters: what can we say about the occurrence and environmental significance of cytotoxic, cytostatic and endocrine therapy drugs? Environ Int 2012;39:73-86.

8. Catastini C, Mullot J-U, Boukari S, Mazellier P, Levi Y, Cervantes P, et al. Assessment of antineoplastic drugs in effluents of two hospitals (Identification de molécules anticancéreuses dans les effluents hospitaliers). J Eur Hydro 2008; 39:80-171.

9. Cancer Care Ontario. Etoposide monograph; 2013. Available from: https://www. cancercare.on.ca/

10. Hande KR PJW, Noone RM, Wilkinson GR, Greco FA, Wolff SN. Pharmacokinetics of high-dose etoposide (VP-16-213) administered to cancer patients. Cancer Res 1984;44:379-82.

11. OECD DRPDoML-CTT, in OECD Series on Testing and Assessment No. 121. Paris: Organisation for Economic Co-operation and Development; 2010. p 182.

12. Galloway T, Depledge M. Immunotoxicity 
in invertebrates: measurement and ecotoxicological relevance. Ecotoxicology 2001;10: 5-23.

13. Team RC. R: A language and environment for statistical computing. Vienna: $\mathrm{R}$ Foundation for Statistical Computing; 2014. Available from: http://www.R-project.org/

14. Wozniak AJ, Ross WE. DNA Damage as a basis for 4'-Demethylepipodophyllotoxin9-(4,6-0-ethylidene- $\beta$-d-glucopyranoside) (etoposide) cytotoxicity. Cancer Res 1983;43:120-4.

15. Russo J, Madec L, Brehélin M. Haemocyte lysosomal fragility facing an environmental reality: a toxicological perspective with atrazine and Lymnaea stagnalis (Gastropoda, Pulmonata) as a test case. Ecotoxicol Environ Saf 2009;72:1719-26.

16. Gust M, Fortier M, Garric J, Fournier M, Gagne F. Effects of short-term exposure to environmentally relevant concentrations of different pharmaceutical mixtures on the immune response of the pond snail Lymnaea stagnalis. Sci Total Environ 2013;445-446:210-8.

17. Gust M, Fortier M, Garric J, Fournier M, Gagne F. Immunotoxicity of surface waters contaminated by municipal effluents to the snail Lymnaea stagnalis. Aquat Toxicol 2013;126:393-403. 